\title{
A New Hybrid Method for Equilibrium Problems, Variational Inequality Problems, Fixed Point Problems, and Zero of Maximal Monotone Operators
}

\author{
Yaqin Wang ${ }^{1,2}$ \\ ${ }^{1}$ Mathematical College, Sichuan University, Chengdu, Sichuan 610064, China \\ ${ }^{2}$ Department of Mathematics, Shaoxing University, Shaoxing 312000, China \\ Correspondence should be addressed to Yaqin Wang, wangyaqin0579@126.com
}

Received 5 August 2011; Accepted 10 October 2011

Academic Editor: Ya Ping Fang

Copyright (C) 2012 Yaqin Wang. This is an open access article distributed under the Creative Commons Attribution License, which permits unrestricted use, distribution, and reproduction in any medium, provided the original work is properly cited.

We introduce a new hybrid iterative scheme for finding a common element of the set of common fixed points of two countable families of relatively quasi-nonexpansive mappings, the set of the variational inequality, the set of solutions of the generalized mixed equilibrium problem, and zeros of maximal monotone operators in a Banach space. We obtain a strong convergence theorem for the sequences generated by this process in a 2-uniformly convex and uniformly smooth Banach space. The results obtained in this paper improve and extend the result of Zeng et al. (2010) and many others.

\section{Introduction}

In 1994, Blum and Oettli [1] introduced equilibrium problems, which have had a great impact and influence on the development of several branches of pure and applied sciences. It has been shown that the equilibrium problem theory provides a novel and unified treatment of a wide class of problems which arise in economics, finance, physics, image reconstruction, ecology, transportation, network, elasticity, and optimization.

Let $E$ be a real Banach space, $E^{*}$ the dual space of $E$, and $C$ a nonempty closed convex subset of $E$. Let $\Theta: C \times C \rightarrow R$ be a bifunction and $\varphi: C \rightarrow R$ a real-valued function. The generalized mixed equilibrium problem (GMEP) of finding $x \in C$ is such that

$$
\Theta(x, y)+\varphi(y)-\varphi(x)+\langle A x, y-x\rangle \geq 0, \quad \forall y \in C
$$


Recently, Zhang [2] considered this problem. Here some special cases of problem (1.1) are stated as follows.

If $A=0$, then problem (1.1) reduces to the following mixed equilibrium problem of finding $x \in C$ such that

$$
\Theta(x, y)+\varphi(y)-\varphi(x) \geq 0, \quad \forall y \in C
$$

which was considered by Ceng and Yao [3]. The set of solutions of this problem is denoted by MEP.

If $\varphi=0$, then problem (1.1) reduces to the following generalized equilibrium problem of finding $x \in C$ such that

$$
\Theta(x, y)+\langle A x, y-x\rangle \geq 0, \quad \forall y \in C
$$

which was studied by S. Takahashi and W. Takahashi [4].

If $\varphi=0$ and $A=0$, then problem (1.1) reduces to the following equilibrium problem of finding $x \in C$ such that

$$
\Theta(x, y) \geq 0, \quad \forall y \in C
$$

The set of solutions of problem (1.4) is denoted by EP.

If $\Theta=0, \varphi=0$, then problem (1.1) reduces to the following classical variational inequality problem of finding $x \in C$ such that

$$
\langle A x, y-x\rangle \geq 0, \quad \forall y \in C
$$

The set of solutions of problem (1.5) is denoted by $\mathrm{VI}(C, A)$.

The problem (1.1) is very general in the sense that it includes, as special cases, numerous problems in physics, optimization, variational inequalities, minimax problems, the Nash equilibrium problem in noncooperative games, and others; see, for instance, [1, 3-7].

The normalized duality mapping from $E$ to $2^{E^{*}}$ is defined by

$$
J x=\left\{f \in E^{*}:\langle x, f\rangle=\|x\|^{2}=\|f\|^{2}\right\}, \quad x \in E,
$$

where $\langle\cdot, \cdot\rangle$ denotes the generalized duality pairing. It is well known that if $E$ is smooth then $J$ is single valued and if $E$ is uniformly smooth then $J$ is uniformly continuous on bounded subsets of $E$. Moreover, if $E$ is a reflexive and strictly convex Banach space with a strictly convex dual, then $J^{-1}$ is single valued, one to one, surjective, and it is the duality mapping from $E^{*}$ into $E$ and thus $J J^{-1}=I_{E^{*}}$ and $J^{-1} J=I_{E}$ (see [8]).

On the other hand, let $W: E \rightrightarrows E^{*}$ be a set-valued mapping. The problem of finding $v \in E$ satisfying $0 \in W v$ contains numerous problems in economics, optimization, and physics. Such $v \in E$ is called a zero point of $W$.

A set-valued mapping $W: E \rightrightarrows E^{*}$ with graph $G(W)=\left\{\left(x, x^{*}\right): x^{*} \in W x\right\}$, domain $D(W)=\{x \in E: W x \neq \emptyset\}$, and range $R(W)=\cup\{W x: x \in D(W)\}$ is said to be monotone if $\left\langle x-y, x^{*}-y^{*}\right\rangle \geq 0$ for all $x^{*} \in W x, y^{*} \in W y$. $W$ is said to be maximal monotone if 
the graph $G(W)$ of $W$ is not properly contained in the graph of any other monotone operator. It is known that $W$ is a maximal monotone if and only if $R(J+r W)=E^{*}$ for all $r>0$ when $E$ is a reflexive, strictly convex, and smooth Banach space (see [9]).

Let $E$ be a smooth, strictly convex, and reflexive Banach space, let $C$ be a nonempty closed convex subset of $E$, and let $W: E \rightrightarrows E^{*}$ be a monotone operator satisfying $D(W) \subset C \subset$ $J^{-1}\left(\cap_{r>0} R(J+r W)\right)$. Then the resolvent of $W$ defined by $J_{r}=(J+r W)^{-1} J$ is a single-valued mapping from $E$ to $D(W)$ for all $r>0$. For $r>0$, the Yosida approximation of $W$ is defined by $W_{r} x=\left(J x-J J_{r} x\right) / r$ for all $x \in E$.

A mapping $A: C \rightarrow E^{*}$ is said to be monotone if, for each $x, y \in C$,

$$
\langle x-y, A x-A y\rangle \geq 0
$$

$A$ is said to be $\gamma$-inverse strongly monotone if there exists a positive real number $\gamma>0$ such that

$$
\langle x-y, A x-A y\rangle \geq \gamma\|A x-A y\|^{2}, \quad \forall x, y \in C .
$$

If $A$ is $\gamma$-inverse strongly monotone, then it is Lipschitz continuous with constant $1 / \gamma$, that is,

$$
\|A x-A y\| \leq\left(\frac{1}{\gamma}\right)\|x-y\|, \quad x, y \in C
$$

Let $E$ be a smooth Banach space. The function $\phi: E \times E \rightarrow R$ defined by

$$
\phi(x, y)=\|x\|^{2}-2\langle x, J y\rangle+\|y\|^{2}, \quad \forall x, y \in E,
$$

is studied by Alber [10], Kamimura and Takahashi [11], and Reich [12]. It follows from the definition of the function $\phi$ that

$$
(\|x\|-\|y\|)^{2} \leq \phi(x, y) \leq(\|x\|+\|y\|)^{2}, \quad \forall x, y \in E .
$$

Observe that, in a Hilbert space $H, \phi(x, y)=\|x-y\|^{2}$, for all $x, y \in H$.

Lemma 1.1 (see [10]). Let $C$ be a nonempty closed and convex subset of a real reflexive, strictly convex, and smooth Banach space $E$, and let $x \in E$. Then there exists a unique element $x_{0} \in C$ such that $\phi\left(x_{0}, x\right)=\min \{\phi(z, x): z \in C\}$.

Let $E$ be a reflexive, strictly convex, and smooth Banach space and $C$ a nonempty closed and convex subset of $E$. The generalized projection mapping, introduced by Alber [10], is a mapping $\Pi_{C}: E \rightarrow C$ that assigns to an arbitrary point $x \in E$, the minimum point of the functional $\phi(x, y)$, that is, $\Pi_{C} x=x_{0}$ due to Lemma 1.1, where $x_{0}$ is the solution to the minimization problem $\phi\left(x_{0}, x\right)=\min \{\phi(z, x): z \in C\}$.

Let $T$ be a mapping from $C$ into itself. $F(T)$ denotes the set of fixed points of $T$. A point $p$ in $C$ is said to be an asymptotic fixed point of $T$ if $C$ contains a sequence $\left\{x_{n}\right\}$ which converges weakly to $p$ such that $\lim _{n \rightarrow \infty}\left\|T x_{n}-x_{n}\right\|=0$. The set of asymptotic fixed points of $T$ 
will be denoted by $\widehat{F}(T)$. A mapping $T$ from $C$ into itself is called nonexpansive if $\|T x-T y\| \leq$ $\|x-y\|$ for all $x, y \in C$ and relatively nonexpansive (see $[13,14])$ if $\widehat{F}(T)=F(T)$ and $\phi(p, T x) \leq$ $\phi(p, x)$ for all $x \in C$ and $p \in F(T)$. T is said to be $\phi$-nonexpansive if $\phi(T x, T y) \leq \phi(x, y)$ for all $x, y \in C$. $T$ is said to be relatively quasi-nonexpansive if $F(T) \neq \emptyset$ and $\phi(p, T x) \leq \phi(p, x)$ for all $x \in C$ and $p \in F(T)$. Note that the class of relatively quasi-nonexpansive mappings is more general than the class of relatively nonexpansive mappings which requires the strong restriction: $\widehat{F}(T)=F(T)$.

When $W$ is a maximal monotone operator, a well-known method for solving the equation $0 \in W v$ in a Hilbert space $H$ is the proximal point algorithm (see [15]): $x_{1}=x \in H$ and

$$
x_{n+1}=J_{r_{n}} x_{n}, \quad n=1,2, \ldots,
$$

where $\left\{r_{n}\right\} \subset(0, \infty)$ and $J_{r}=(I+r W)^{-1}$ for all $r>0$ is the resolvent operator for $W$, then Rockafellar proved that the sequence $\left\{x_{n}\right\}$ converges weakly to an element of $W^{-1} 0$.

The modifications of the proximal point algorithm for different operators have been investigated by many authors. Kohsaka and Takahashi [16] considered the following Algorithm (1.13) in a smooth and uniformly convex Banach space:

$$
x_{n+1}=J^{-1}\left(\beta_{n} J\left(x_{1}\right)+\left(1-\beta_{n}\right) J\left(J_{r_{n}} x_{n}\right)\right), \quad n=1,2, \ldots,
$$

and Kamimura et al. [17] considered Algorithm (1.14) in a uniformly smooth and uniformly convex Banach space:

$$
x_{n+1}=J^{-1}\left(\beta_{n} J\left(x_{n}\right)+\left(1-\beta_{n}\right) J\left(J_{r_{n}} x_{n}\right)\right), \quad n=1,2, \ldots
$$

They showed that Algorithm (1.13) converges strongly and Algorithm (1.14) converges weakly provided that the sequences $\left\{\beta_{n}\right\},\left\{r_{n}\right\}$ of real numbers are chosen appropriately.

Recently, Saewan and Kumam [18] proposed the following iterative scheme: for an initial $x_{0} \in E$ with $x_{1}=\Pi_{C_{1}} x_{0}$ and $C_{1}=C$

$$
\begin{aligned}
& \omega_{n}=\Pi_{C} J^{-1}\left(J x_{n}-\lambda_{n} A x_{n}\right), \\
& z_{n}=J^{-1}\left(\beta_{n} J x_{n}+\left(1-\beta_{n}\right) J T_{n} J_{r_{n}} \omega_{n}\right), \\
& y_{n}=J^{-1}\left(\alpha_{n} J x_{n}+\left(1-\alpha_{n}\right) J S_{n} z_{n}\right), \\
& u_{n}=K_{r_{n}} y_{n}, \\
& C_{n+1}=\left\{z \in C_{n}: \phi\left(z, u_{n}\right) \leq \phi\left(z, z_{n}\right) \leq \phi\left(z, x_{n}\right)\right\}, \\
& x_{n+1}=\prod_{C_{n+1}} x_{0}, \quad n \geq 0,
\end{aligned}
$$

where $K_{r}$ is the same as in Lemma 2.8 and they obtained a strong convergence theorem. 
In 2010, Zeng et al. [19] introduced the following hybrid iterative process: let $x_{0} \in E$ be chosen arbitrarily,

$$
\begin{aligned}
& \tilde{x}_{n}=J^{-1}\left(\alpha_{n} J x_{0}+\left(1-\alpha_{n}\right)\left(\beta_{n} J x_{n}+\left(1-\beta_{n}\right) J J_{r_{n}} v_{n}\right)\right), \\
& y_{n}=J^{-1}\left(\widetilde{\alpha}_{n} J x_{0}+\left(1-\widetilde{\alpha}_{n}\right)\left(\tilde{\beta}_{n} J \tilde{x}_{n}+\left(1-\tilde{\beta}_{n}\right) J \widetilde{J}_{r_{n}} \tilde{x}_{n}\right)\right), \\
& u_{n}=K_{r_{n}} y_{n}, \\
& H_{n}=\left\{z \in C: \phi\left(z, u_{n}\right) \leq\left(\tilde{\alpha}_{n}+\left(1-\tilde{\alpha}_{n}\right) \alpha_{n}\right) \phi\left(z, x_{0}\right)+\left(1-\tilde{\alpha}_{n}\right)\left(1-\alpha_{n}\right) \phi\left(z, x_{n}\right)\right\}, \\
& W_{n}=\left\{z \in C:\left\langle x_{n}-z, J x_{0}-J x_{n}\right\rangle \geq 0\right\}, \\
& x_{n+1}=\Pi_{H_{n} \cap W_{n}} x_{0}, \quad n \geq 0 .
\end{aligned}
$$

Then they proved some strong and weak convergence theorems.

Very recently, for mixed equilibrium problems, variational inequality problems, fixed point problems, and zeros of maximal monotone operators, many authors have studied them and obtained many new results, see, for instance, [20-23].

On the other hand, Nakajo et al. [24] introduced the following condition. Let $C$ be a nonempty closed convex subset of a Hilbert space $H$, let $\left\{T_{n}\right\}$ be a family of mappings of $C$ into itself with $F=\cap_{n=1}^{\infty} F\left(T_{n}\right) \neq \emptyset$, and $\omega_{w}\left(z_{n}\right)$ denotes the set of all weak subsequential limits of a bounded sequence $\left\{z_{n}\right\}$ in $C .\left\{T_{n}\right\}$ is said to satisfy the NST-condition if, for every bounded sequence $\left\{z_{n}\right\}$ in $C$,

$$
\lim _{n \rightarrow \infty}\left\|z_{n}-S_{n} z_{n}\right\|=0 \text { implies that } \omega_{w}\left(z_{n}\right) \subset F .
$$

Motivated and inspired by the above work, the purpose of this paper is to introduce a new hybrid projection iterative scheme which converges strongly to a common element of the solution set of a generalized mixed equilibrium problem, the solution set of a variational inequality problem, and the set of common fixed points of two countable families of relatively quasi-nonexpansive mappings and zero of maximal monotone operators in Banach spaces.

\section{Preliminaries}

Let $E$ be a normed linear space with $\operatorname{dim} E \geq 2$. The modulus of smoothness of $E$ is the function $\rho_{E}:[0,+\infty) \rightarrow[0,+\infty)$ defined by

$$
\rho_{E}(\tau):=\sup \left\{\frac{\|x+y\|+\|x-y\|}{2}-1:\|x\|=1,\|y\|=\tau\right\} .
$$

The space $E$ is said to be smooth if $\rho_{E}(\tau)>0$, for all $\tau>0$, and $E$ is called uniformly smooth if and only if $\lim _{t \rightarrow 0^{+}}\left(\rho_{E}(t) / t\right)=0$.

The modulus of convexity of $E$ is the function $\delta_{E}:(0,2] \rightarrow[0,1]$ defined by

$$
\delta_{E}(\varepsilon):=\inf \left\{1-\left\|\frac{x+y}{2}\right\|:\|x\|=\|y\|=1 ; \varepsilon=\|x-y\|\right\} .
$$


$E$ is called uniformly convex if and only if $\delta_{E}(\varepsilon)>0$ for every $\varepsilon \in(0,2]$. Let $p>1$, then $E$ is said to be $p$-uniformly convex if there exists a constant $c>0$ such that $\delta_{E}(\varepsilon) \geq c \varepsilon^{p}$ for every $\varepsilon \in(0,2]$. Observe that every $p$-uniformly convex is uniformly convex. It is well known (see, e.g., [7]) that

$$
L_{p}\left(l_{p}\right) \text { or } W_{m}^{p} \text { is } \begin{cases}p \text {-uniformly convex } & \text { if } p \geq 2 \\ 2 \text {-uniformly convex } & \text { if } 1<p \leq 2\end{cases}
$$

In what follows, we will make use of the following lemmas.

Lemma 2.1 (see [7]). Let E be a 2-uniformly convex and smooth Banach space. Then, for all $x, y \in E$, one has

$$
\|x-y\| \leq \frac{2}{c^{2}}\|J x-J y\|
$$

where $J$ is the normalized duality mapping of $E$ and $1 / c(0<c \leq 1)$ is the 2-uniformly convex constant of $E$.

Lemma 2.2 (see $[10,11])$. Let $E$ be a real smooth, strictly convex, and reflexive Banach space and $C$ a nonempty closed convex subset. Then the following conclusions hold:

(1) $\phi\left(y, \Pi_{C} x\right)+\phi\left(\Pi_{C} x, x\right) \leq \phi(y, x), \forall x \in E, y \in C$;

(2) suppose $x \in E$ and $z \in C$, then

$$
z=\Pi_{C} x \Longleftrightarrow\langle z-y, J x-J z\rangle \geq 0, \quad \forall y \in C
$$

Lemma 2.3 (see [11]). Let E be a real smooth and uniformly convex Banach space, and let $\left\{x_{n}\right\}$ and $\left\{y_{n}\right\}$ be two sequences of $E$. If either $\left\{x_{n}\right\}$ or $\left\{y_{n}\right\}$ is bounded and $\phi\left(x_{n}, y_{n}\right) \rightarrow 0$ as $n \rightarrow \infty$, then $x_{n}-y_{n} \rightarrow 0$ as $n \rightarrow \infty$.

Lemma 2.4 (see [25]). Let $E$ be a real smooth Banach space, and let $A: E \rightrightarrows E^{*}$ be a maximal monotone mapping, then $A^{-1}(0)$ is a closed and convex subset of $E$.

We denote by $N_{C}(v)$ the normal cone for $C$ at a point $v \in C$, that is, $N_{C}(v):=\left\{x^{*} \in\right.$ $E^{*}:\left\langle v-y, x^{*}\right\rangle \geq 0$ for all $\left.y \in C\right\}$. In the following, we will use the following Lemma.

Lemma 2.5 (see [15]). Let $C$ be a nonempty closed convex subset of a Banach space $E$, and let $A$ be a monotone and hemicontinuous operator of $C$ into $E^{*}$. Let $T \subset E \times E^{*}$ be an operator defined as follows:

$$
T v= \begin{cases}A v+N_{C}(v), & v \in C, \\ \emptyset, & v \notin C .\end{cases}
$$

Then $T$ is maximal monotone and $T^{-1} 0=\operatorname{VI}(C, A)$. 
We make use of the function $V: E \times E^{*} \rightarrow R$ defined by

$$
V\left(x, x^{*}\right)=\|x\|^{2}-2\left\langle x, x^{*}\right\rangle+\|x\|^{2}, \quad \forall x \in E, x^{*} \in E^{*},
$$

studied by Alber [10]; that is, $V\left(x, x^{*}\right)=\phi\left(x, J^{-1} x^{*}\right)$ for all $x \in E$ and $x^{*} \in E^{*}$. We know the following lemma.

Lemma 2.6 (see [10]). Let E be a reflexive strictly convex and smooth Banach space with $E^{*}$ as its dual. Then

$$
V\left(x, x^{*}\right)+2\left\langle J^{-1} x^{*}-x, y^{*}\right\rangle \leq V\left(x, x^{*}+y^{*}\right)
$$

for all $x \in E$ and $x^{*}, y^{*} \in E^{*}$.

Lemma 2.7 (see [26]). Let E be a uniformly convex Banach space, and let $B_{r}(0)=\{x \in E:\|x\| \leq r\}$ be a closed ball of $E$. Then there exists a continuous strictly increasing convex function $g:[0, \infty) \rightarrow$ $[0, \infty)$ with $g(0)=0$ such that

$$
\|\lambda x+\mu y+\gamma z\|^{2} \leq \lambda\|x\|^{2}+\mu\|y\|^{2}+\gamma\|z\|^{2}-\lambda \mu g(\|x-y\|),
$$

for all $x, y, z \in B_{r}(0)$ and $\lambda, \mu, \gamma \in[0,1]$ with $\lambda+\mu+\gamma=1$. ditions:

For solving the equilibrium problem, let us assume that $\Theta$ satisfies the following con-

(A1) $\Theta(x, x)=0$ for all $x \in C$;

(A2) $\Theta$ is monotone, that is, $\Theta(x, y)+\Theta(y, x) \leq 0$ for all $x, y \in C$;

(A3) for each $x, y, z \in C$,

$$
\lim _{t \rightarrow 0} \Theta(t z+(1-t) x, y) \leq \Theta(x, y)
$$

(A4) for each $x \in C, y \mapsto \Theta(x, y)$ is convex and lower semicontinuous.

Lemma 2.8 (see [2]). Let $C$ be a closed subset of a smooth, strictly convex, and reflexive Banach space $E$. Let $B: C \rightarrow E^{*}$ be a continuous and monotone mapping, let $\varphi: C \rightarrow R$ be a lower semicontinuous and convex function, and let $\Theta$ be a bifunction from $C \times C$ to $R$ satisfying (A1)-(A4). For $r>0$ and $x \in E$, then there exists $u \in C$ such that

$$
\Theta(u, y)+\langle B u, y-u\rangle+\varphi(y)-\varphi(u)+\frac{1}{r}\langle y-u, J u-J x\rangle \geq 0, \quad \forall y \in C .
$$

Define a mapping $K_{r}: E \rightarrow C$ as follows:

$$
K_{r}(x)=\left\{u \in C: \Theta(u, y)+\langle B u, y-u\rangle+\varphi(y)-\varphi(u)+\frac{1}{r}\langle y-u, J u-J x\rangle \geq 0, \forall y \in C\right\},
$$


for all $x \in E$. Then, the following conclusions hold:

(1) $K_{r}$ is single valued;

(2) $K_{r}$ is firmly nonexpansive, that is, for all $x, y \in E,\left\langle K_{r} x-K_{r} y, J K_{r} x-J K_{r} y\right\rangle \leq\left\langle K_{r} x-\right.$ $\left.K_{r} y, J x-J y\right\rangle$;

(3) $F\left(K_{r}\right)=$ GMEP;

(4) GMEP is closed and convex;

(5) $\phi\left(p, K_{r} z\right)+\phi\left(K_{r} z, z\right) \leq \phi(p, z), \quad \forall p \in F\left(K_{r}\right), z \in E$.

Lemma 2.9 (see [27]). Let $E$ be a smooth, strictly convex, and reflexive Banach space, let $C$ be a nonempty closed convex subset of $E$, and let $W: E \rightrightarrows E^{*}$ be a monotone operator satisfying $D(W) \subset$ $C \subset J^{-1}\left(\cap_{r>0} R(J+r W)\right)$. Let $r>0$, and let $J_{r}$ and $W_{r}$ be the resolvent and the Yosida approximation of $W$, respectively. Then the following hold:

(i) $\phi\left(u, J_{r} x\right)+\phi\left(J_{r} x, x\right) \leq \phi(u, x)$, for all $x \in C, u \in W^{-1} 0$;

(ii) $\left(J_{r} x, W_{r} x\right) \in G(W)$, for all $x \in C$;

(iii) $F\left(J_{r}\right)=W^{-1} 0$.

Lemma 2.10 (see [28]). Let E be a real uniformly smooth and strictly convex Banach space and $C$ a nonempty closed convex subset of $E$. Let $S: C \rightarrow C$ be a relatively quasi-nonexpansive mapping. Then $F(S)$ is a closed convex subset of $C$.

\section{Strong Convergence Theorems}

In this section, let $T, \tilde{T}: E \rightrightarrows E^{*}$ be two maximal monotone operators satisfying $D(T), D(\widetilde{T}) \subset$ C. We denote the resolvent operators of $T$ and $\widetilde{T}$ by $J_{r}=(J+r T)^{-1} J$ and $\tilde{J}_{r}=(J+r \tilde{T})^{-1} J$ for each $r>0$, respectively. For each $r>0$, the Yosida approximations of $T$ and $\tilde{T}$ are defined by $A_{r}=\left(J-J J_{r}\right) / r$ and $\widetilde{A}_{r}=\left(J-J \widetilde{J}_{r}\right) / r$, respectively. It is known that

$$
A_{r} x \in T\left(J_{r} x\right), \tilde{A}_{r} x \in \tilde{T}\left(\tilde{J}_{r} x\right), \quad \text { for each } r>0, x \in E
$$

Theorem 3.1. Let $E$ be a real uniformly smooth and 2-uniformly convex Banach space and $C$ a nonempty, closed, and convex subset of $E$. Let $A$ be a $\gamma$-inverse strongly monotone mapping of $C$ into $E^{*}$ satisfying $\|A x\| \leq\|A x-A p\|$ for all $x \in C$ and $p \in V I(C, A)$. Let $B: C \rightarrow E^{*}$ be a monotone continuous mapping, and let $\left\{T_{n}\right\},\left\{S_{n}\right\}$ be two countable families of relatively quasi-nonexpansive mappings from C into itself satisfying NST-conditions such that $\Omega:=\left(\cap_{n=0}^{\infty} F\left(T_{n}\right)\right) \cap\left(\cap_{n=0}^{\infty} F\left(S_{n}\right)\right) \cap$ $\operatorname{VI}(C, A) \cap G M E P \cap T^{-1} 0 \cap \widetilde{T}^{-1} 0 \neq \emptyset$. Suppose that $0<a<\lambda_{n}<b<\left(c^{2} \gamma\right) / 2$, where $c$ is the constant 
Journal of Applied Mathematics

in (2.4). Let $\left\{t_{n}\right\} \subset\left[c^{*},+\infty\right)$ for some $c^{*}>0$ and $\left\{r_{n}\right\} \subset(0,+\infty)$ satisfy $\lim _{\inf _{n \rightarrow \infty}} r_{n}>0$. Let $\left\{x_{n}\right\}$ be the sequence generated by

$$
\begin{aligned}
& x_{0} \in C, \text { chosen arbitrarily, } \\
& v_{n}=\Pi_{C} J^{-1}\left(J x_{n}-\lambda_{n} A x_{n}\right), \\
& z_{n}=J^{-1}\left(\alpha_{n} J x_{0}+\left(1-\alpha_{n}\right)\left(\beta_{n} J x_{n}+\left(1-\beta_{n}\right) J S_{n} J_{r_{n}} v_{n}\right)\right), \\
& y_{n}=J^{-1}\left(\tilde{\alpha}_{n} J x_{0}+\left(1-\tilde{\alpha}_{n}\right)\left(\tilde{\beta}_{n} J z_{n}+\left(1-\tilde{\beta}_{n}\right) J T_{n} \tilde{J}_{r_{n}} z_{n}\right)\right), \\
& u_{n}=K_{t_{n}} y_{n}, \\
& H_{n}=\left\{z \in C: \phi\left(z, u_{n}\right) \leq\left(\tilde{\alpha}_{n}+\left(1-\tilde{\alpha}_{n}\right) \alpha_{n}\right) \phi\left(z, x_{0}\right)+\left(1-\tilde{\alpha}_{n}\right)\left(1-\alpha_{n}\right) \phi\left(z, x_{n}\right)\right\}, \\
& W_{n}=\left\{z \in C:\left\langle x_{n}-z, J x_{0}-J x_{n}\right\rangle \geq 0\right\}, \\
& x_{n+1}=\Pi_{H_{n} \cap W_{n}} x_{0}, \quad n \geq 0,
\end{aligned}
$$

where $J$ is the normalized duality mapping, $\left\{\alpha_{n}\right\},\left\{\beta_{n}\right\},\left\{\tilde{\alpha}_{n}\right\}$, and $\left\{\tilde{\beta}_{n}\right\}$ are four sequences in $[0,1]$, and $K_{r}$ is defined by $(*)$. The following conditions hold:

(i) $\lim _{n \rightarrow \infty} \alpha_{n}=\lim _{n \rightarrow \infty} \tilde{\alpha}_{n}=0$;

(ii) $\lim \inf _{n \rightarrow \infty} \beta_{n}\left(1-\beta_{n}\right)>0$;

(iii) $\lim \inf _{n \rightarrow \infty} \tilde{\beta}_{n}\left(1-\tilde{\beta}_{n}\right)>0$.

Then $\left\{x_{n}\right\}$ converges strongly to $\Pi_{\Omega} x_{0}$.

Proof. We have the following steps.

Step 1. First we prove that $H_{n}$ and $W_{n}$ are both closed and convex and $\Omega \subset H_{n} \cap W_{n}$, for all $n \geq 0$.

In fact, it follows from Lemmas 2.4, 2.5, 2.8, and 2.10 that $\Omega$ is closed and convex. It is obvious that $W_{n}$ is closed and convex for each $n \geq 0$. Let $\gamma_{n}=\widetilde{\alpha}_{n}+\left(1-\tilde{\alpha}_{n}\right) \alpha_{n}, w_{n}=J_{r_{n}} v_{n}, \tilde{z}_{n}=$ $\tilde{J}_{r_{n}} z_{n}$. For any $z \in C$,

$$
\phi\left(z, u_{n}\right) \leq \gamma_{n} \phi\left(z, x_{0}\right)+\left(1-\gamma_{n}\right) \phi\left(z, x_{n}\right)
$$

is equivalent to

$$
-2\left\langle z, J u_{n}\right\rangle+\left\|u_{n}\right\|^{2} \leq-2 \gamma_{n}\left\langle z, J x_{0}\right\rangle+\gamma_{n}\left\|x_{0}\right\|^{2}+\left(1-\gamma_{n}\right)\left(-2\left\langle z, J x_{n}\right\rangle+\left\|x_{n}\right\|^{2}\right),
$$

which implies that $H_{n}$ is closed and convex for each $n \geq 0$. Next, we prove that $\Omega \subset H_{n} \cap$ $W_{n}$, for all $n \geq 0$. For any given $p \in \Omega$, by Lemma 2.9 we have

$$
\begin{aligned}
& \phi\left(p, w_{n}\right)=\phi\left(p, J_{r_{n}} v_{n}\right) \leq \phi\left(p, v_{n}\right) \\
& \phi\left(p, \widetilde{z}_{n}\right)=\phi\left(p, \widetilde{J}_{r_{n}} z_{n}\right) \leq \phi\left(p, z_{n}\right) .
\end{aligned}
$$


Since $T_{n}, S_{n}$ are relatively quasi-nonexpansive, from the definition of $\phi(x, y)$, the convexity of $\|\cdot\|^{2}$, and (3.5), we have

$$
\begin{aligned}
& \phi\left(p, y_{n}\right)=\phi\left(p, J^{-1}\left(\tilde{\alpha}_{n} J x_{0}+\left(1-\tilde{\alpha}_{n}\right)\left(\tilde{\beta}_{n} J z_{n}+\left(1-\tilde{\beta}_{n}\right) J T_{n} \widetilde{z}_{n}\right)\right)\right) \\
& =\|p\|^{2}-2 \tilde{\alpha}_{n}\left\langle p, J x_{0}\right\rangle-2\left(1-\tilde{\alpha}_{n}\right) \tilde{\beta}_{n}\left\langle p, J z_{n}\right\rangle-2\left(1-\tilde{\alpha}_{n}\right)\left(1-\tilde{\beta}_{n}\right)\left\langle p, J T_{n} \tilde{z}_{n}\right\rangle \\
& +\left\|\widetilde{\alpha}_{n} J x_{0}+\left(1-\widetilde{\alpha}_{n}\right)\left(\tilde{\beta}_{n} J z_{n}+\left(1-\tilde{\beta}_{n}\right) J T_{n} \widetilde{z}_{n}\right)\right\|^{2} \\
& \leq\|p\|^{2}-2 \tilde{\alpha}_{n}\left\langle p, J x_{0}\right\rangle-2\left(1-\tilde{\alpha}_{n}\right) \tilde{\beta}_{n}\left\langle p, J z_{n}\right\rangle-2\left(1-\tilde{\alpha}_{n}\right)\left(1-\tilde{\beta}_{n}\right)\left\langle p, J T_{n} \widetilde{z}_{n}\right\rangle \\
& +\widetilde{\alpha}_{n}\left\|x_{0}\right\|^{2}+\left(1-\widetilde{\alpha}_{n}\right)\left(\tilde{\beta}_{n}\left\|z_{n}\right\|^{2}+\left(1-\tilde{\beta}_{n}\right)\left\|T_{n} \tilde{z}_{n}\right\|^{2}\right) \\
& =\tilde{\alpha}_{n} \phi\left(p, x_{0}\right)+\left(1-\tilde{\alpha}_{n}\right) \tilde{\beta}_{n} \phi\left(p, z_{n}\right)+\left(1-\tilde{\alpha}_{n}\right)\left(1-\tilde{\beta}_{n}\right) \phi\left(p, T_{n} \tilde{z}_{n}\right) \\
& \leq \tilde{\alpha}_{n} \phi\left(p, x_{0}\right)+\left(1-\tilde{\alpha}_{n}\right) \tilde{\beta}_{n} \phi\left(p, z_{n}\right)+\left(1-\widetilde{\alpha}_{n}\right)\left(1-\tilde{\beta}_{n}\right) \phi\left(p, \tilde{z}_{n}\right) \\
& \leq \tilde{\alpha}_{n} \phi\left(p, x_{0}\right)+\left(1-\tilde{\alpha}_{n}\right) \phi\left(p, z_{n}\right), \\
& \phi\left(p, z_{n}\right)=\phi\left(p, J^{-1}\left(\alpha_{n} J x_{0}+\left(1-\alpha_{n}\right)\left(\beta_{n} J x_{n}+\left(1-\beta_{n}\right) J S_{n} w_{n}\right)\right)\right) \\
& \leq\|p\|^{2}-2 \alpha_{n}\left\langle p, J x_{0}\right\rangle-2\left(1-\alpha_{n}\right) \beta_{n}\left\langle p, J x_{n}\right\rangle-2\left(1-\alpha_{n}\right)\left(1-\beta_{n}\right)\left\langle p, J S_{n} w_{n}\right\rangle \\
& +\alpha_{n}\left\|x_{0}\right\|^{2}+\left(1-\alpha_{n}\right)\left(\beta_{n}\left\|x_{n}\right\|^{2}+\left(1-\beta_{n}\right)\left\|S_{n} w_{n}\right\|^{2}\right) \\
& =\alpha_{n} \phi\left(p, x_{0}\right)+\left(1-\alpha_{n}\right) \beta_{n} \phi\left(p, x_{n}\right)+\left(1-\alpha_{n}\right)\left(1-\beta_{n}\right) \phi\left(p, S_{n} w_{n}\right) \\
& \leq \alpha_{n} \phi\left(p, x_{0}\right)+\left(1-\alpha_{n}\right) \beta_{n} \phi\left(p, x_{n}\right)+\left(1-\alpha_{n}\right)\left(1-\beta_{n}\right) \phi\left(p, w_{n}\right) \\
& \leq \alpha_{n} \phi\left(p, x_{0}\right)+\left(1-\alpha_{n}\right) \beta_{n} \phi\left(p, x_{n}\right)+\left(1-\alpha_{n}\right)\left(1-\beta_{n}\right) \phi\left(p, v_{n}\right) \text {. }
\end{aligned}
$$

Moreover, it follows from Lemmas 2.2 and 2.6 that

$$
\begin{aligned}
\phi\left(p, v_{n}\right) \leq & \phi\left(p, J^{-1}\left(J x_{n}-\lambda_{n} A x_{n}\right)\right) \\
\leq & V\left(p, J x_{n}-\lambda_{n} A x_{n}\right) \\
\leq & V\left(p, J x_{n}-\lambda_{n} A x_{n}+\lambda_{n} A x_{n}\right)-2\left\langle J^{-1}\left(J x_{n}-\lambda_{n} A x_{n}\right)-p, \lambda_{n} A x_{n}\right\rangle \\
= & \phi\left(p, x_{n}\right)-2 \lambda_{n}\left\langle x_{n}-p, A x_{n}-A p\right\rangle-2 \lambda_{n}\left\langle x_{n}-p, A p\right\rangle \\
& -2 \lambda_{n}\left\langle J^{-1}\left(J x_{n}-\lambda_{n} A x_{n}\right)-x_{n}, A x_{n}\right\rangle .
\end{aligned}
$$


Since $p \in \operatorname{VI}(C, A), A$ is $\gamma$-inverse strongly monotone, from the above inequality, Lemma 2.1, and the fact that $\|A x\| \leq\|A x-A p\|$ for all $x \in C$ and $p \in \operatorname{VI}(C, A)$, we obtain

$$
\begin{aligned}
\phi\left(p, v_{n}\right) & \leq \phi\left(p, x_{n}\right)-2 \lambda_{n} \gamma\left\|A x_{n}-A p\right\|^{2}+2 \lambda_{n}\left\|J^{-1}\left(J x_{n}-\lambda_{n} A x_{n}\right)-x_{n}\right\|\left\|A x_{n}\right\| \\
& \leq \phi\left(p, x_{n}\right)-2 \lambda_{n} \gamma\left\|A x_{n}-A p\right\|^{2}+\frac{4}{c^{2}} \lambda_{n}^{2}\left\|A x_{n}-A p\right\|^{2} \\
& =\phi\left(p, x_{n}\right)+2 \lambda_{n}\left(\frac{2}{c^{2}} \lambda_{n}-\gamma\right)\left\|A x_{n}-A p\right\|^{2} \\
& \leq \phi\left(p, x_{n}\right) .
\end{aligned}
$$

From (3.7)-(3.9), we have

$$
\phi\left(p, z_{n}\right) \leq \alpha_{n} \phi\left(p, x_{0}\right)+\left(1-\alpha_{n}\right) \phi\left(p, x_{n}\right)
$$

So from (3.6) and (3.10), we have

$$
\phi\left(p, y_{n}\right) \leq\left(\widetilde{\alpha}_{n}+\left(1-\widetilde{\alpha}_{n}\right) \alpha_{n}\right) \phi\left(p, x_{0}\right)+\left(1-\widetilde{\alpha}_{n}\right)\left(1-\alpha_{n}\right) \phi\left(p, x_{n}\right) .
$$

By Lemma 2.8(5) and (3.11), we have

$$
\begin{aligned}
\phi\left(p, u_{n}\right) & =\phi\left(p, K_{t_{n}} y_{n}\right) \leq \phi\left(p, y_{n}\right) \\
& \leq\left(\widetilde{\alpha}_{n}+\left(1-\widetilde{\alpha}_{n}\right) \alpha_{n}\right) \phi\left(p, x_{0}\right)+\left(1-\widetilde{\alpha}_{n}\right)\left(1-\alpha_{n}\right) \phi\left(p, x_{n}\right) .
\end{aligned}
$$

Therefore, $p \in H_{n}$; that is $\Omega \subset H_{n}$ for each $n \geq 0$.

Next we prove that $\Omega \subset H_{n} \cap W_{n}$ for each $n \geq 0$ by induction. For $n=0, W_{0}=C$, thus $\Omega \subset H_{0} \cap W_{0}$. Suppose that $\Omega \subset H_{n} \cap W_{n}$ for some $n \geq 1$. Since $x_{n+1}=\Pi_{H_{n} \cap W_{n}} x_{0}$, by Lemma 2.2, for any $q \in H_{n} \cap W_{n}$, we have

$$
\left\langle x_{n+1}-q, J x_{0}-J x_{n+1}\right\rangle \geq 0 .
$$

Since $\Omega \subset H_{n} \cap W_{n}$, for any $p \in \Omega$, we have

$$
\left\langle x_{n+1}-p, J x_{0}-J x_{n+1}\right\rangle \geq 0,
$$

which implies that $p \in W_{n+1}$, that is, $\Omega \subset H_{n} \cap W_{n}$ for each $n \geq 0$.

Step 2. Next we prove that $\left\|w_{n}-S_{n} w_{n}\right\| \rightarrow 0,\left\|\tilde{z}_{n}-T_{n} \tilde{z}_{n}\right\| \rightarrow 0(n \rightarrow \infty)$.

Similar to the proof of Step 3 in [19, Theorem 3.1], we have that $\left\{\phi\left(x_{n}, x_{0}\right)\right\}$ is nondecreasing and bounded and $\phi\left(x_{n+1}, x_{n}\right) \rightarrow 0(n \rightarrow \infty)$. So $\left\{x_{n}\right\}$ is bounded, then, by (3.5)-(3.12), we obtain that $\left\{u_{n}\right\},\left\{z_{n}\right\},\left\{v_{n}\right\},\left\{w_{n}\right\},\left\{\tilde{z}_{n}\right\}$, and $\left\{y_{n}\right\}$ are all bounded. Furthermore, $\left\{S_{n} w_{n}\right\}$ and $\left\{T_{n} \tilde{z}_{n}\right\}$ are both bounded. By Lemma 2.3, we have

$$
\left\|x_{n}-x_{n+1}\right\| \longrightarrow 0 \quad(n \longrightarrow \infty)
$$


Since $x_{n+1}=\Pi_{H_{n} \cap W_{n}} x_{0} \in H_{n}$ and by condition (i), we have

$$
\phi\left(x_{n+1}, u_{n}\right) \leq\left(\widetilde{\alpha}_{n}+\left(1-\widetilde{\alpha}_{n}\right) \alpha_{n}\right) \phi\left(x_{n+1}, x_{0}\right)+\left(1-\widetilde{\alpha}_{n}\right)\left(1-\alpha_{n}\right) \phi\left(x_{n+1}, x_{n}\right) \longrightarrow 0 \quad(n \longrightarrow \infty),
$$

which together with Lemma 2.3 implies that $\left\|x_{n+1}-u_{n}\right\| \rightarrow 0(n \rightarrow \infty)$. So we obtain

$$
\left\|x_{n}-u_{n}\right\| \longrightarrow 0 \quad(n \longrightarrow \infty)
$$

Let $a_{n}=J^{-1}\left(\beta_{n} J x_{n}+\left(1-\beta_{n}\right) J S_{n} J_{r_{n}} v_{n}\right), b_{n}=J^{-1}\left(\tilde{\beta}_{n} J z_{n}+\left(1-\widetilde{\beta}_{n}\right) J T_{n} \widetilde{J}_{r_{n}} z_{n}\right)$. It follows from the boundedness of $\left\{x_{n}\right\}$ that $\left\{S_{n} w_{n}\right\}$ and $\left\{T_{n} \tilde{z}_{n}\right\}$ are bounded. Let $r=\sup \left\{\left\|x_{n}\right\|\right.$, $\left.\left\|z_{n}\right\|,\left\|T_{n} \tilde{z}_{n}\right\|,\left\|S_{n} w_{n}\right\|\right\}$. By Lemma 2.7, (3.5), and (3.9), for any $p \in \Omega$, we obtain

$$
\begin{aligned}
\phi\left(p, a_{n}\right)= & \phi\left(p, J^{-1}\left(\beta_{n} J x_{n}+\left(1-\beta_{n}\right) J S_{n} J_{r_{n}} v_{n}\right)\right) \\
= & \|p\|^{2}-2\left\langle p, \beta_{n} J x_{n}+\left(1-\beta_{n}\right) J S_{n} J_{r_{n}} v_{n}\right\rangle+\left\|\beta_{n} J x_{n}+\left(1-\beta_{n}\right) J S_{n} J_{r_{n}} v_{n}\right\|^{2} \\
\leq & \|p\|^{2}-2 \beta_{n}\left\langle p, J x_{n}\right\rangle-2\left(1-\beta_{n}\right)\left\langle p, J S_{n} J_{r_{n}} v_{n}\right\rangle \\
& +\beta_{n}\left\|x_{n}\right\|^{2}+\left(1-\beta_{n}\right)\left\|S_{n} J_{r_{n}} v_{n}\right\|^{2}-\beta_{n}\left(1-\beta_{n}\right) g\left(\left\|J x_{n}-J S_{n} w_{n}\right\|\right) \\
\leq & \beta_{n} \phi\left(p, x_{n}\right)+\left(1-\beta_{n}\right) \phi\left(p, S_{n} w_{n}\right)-\beta_{n}\left(1-\beta_{n}\right) g\left(\left\|J x_{n}-J S_{n} w_{n}\right\|\right) \\
\leq & \beta_{n} \phi\left(p, x_{n}\right)+\left(1-\beta_{n}\right) \phi\left(p, w_{n}\right)-\beta_{n}\left(1-\beta_{n}\right) g\left(\left\|J x_{n}-J S_{n} w_{n}\right\|\right) \\
\leq & \phi\left(p, x_{n}\right)-\beta_{n}\left(1-\beta_{n}\right) g\left(\left\|J x_{n}-J S_{n} w_{n}\right\|\right) \\
\phi\left(p, b_{n}\right)= & \phi\left(p, J^{-1}\left(\tilde{\beta}_{n} J z_{n}+\left(1-\tilde{\beta}_{n}\right) J T_{n} \tilde{z}_{n}\right)\right) \\
\leq & \tilde{\beta}_{n} \phi\left(p, z_{n}\right)+\left(1-\tilde{\beta}_{n}\right) \phi\left(p, T_{n} \tilde{z}_{n}\right)-\tilde{\beta}_{n}\left(1-\tilde{\beta}_{n}\right) g\left(\left\|J z_{n}-J T_{n} \widetilde{z}_{n}\right\|\right) \\
\leq & \tilde{\beta}_{n} \phi\left(p, z_{n}\right)+\left(1-\tilde{\beta}_{n}\right) \phi\left(p, \tilde{z}_{n}\right)-\tilde{\beta}_{n}\left(1-\tilde{\beta}_{n}\right) g\left(\left\|J z_{n}-J T_{n} \tilde{z}_{n}\right\|\right) \\
\leq & \phi\left(p, z_{n}\right)-\tilde{\beta}_{n}\left(1-\tilde{\beta}_{n}\right) g\left(\left\|J z_{n}-J T_{n} \tilde{z}_{n}\right\|\right) .
\end{aligned}
$$

It follows from (3.10), (3.12), and (3.19) that

$$
\begin{aligned}
& \phi\left(p, u_{n}\right) \leq \phi\left(p, y_{n}\right) \\
& =\phi\left(p, J^{-1}\left(\tilde{\alpha}_{n} J x_{0}+\left(1-\tilde{\alpha}_{n}\right) J b_{n}\right)\right) \\
& \leq \tilde{\alpha}_{n} \phi\left(p, x_{0}\right)+\left(1-\tilde{\alpha}_{n}\right) \phi\left(p, b_{n}\right) \\
& \leq \tilde{\alpha}_{n} \phi\left(p, x_{0}\right)+\left(1-\tilde{\alpha}_{n}\right)\left(\phi\left(p, z_{n}\right)-\tilde{\beta}_{n}\left(1-\tilde{\beta}_{n}\right) g\left(\left\|J z_{n}-J T_{n} \widetilde{z}_{n}\right\|\right)\right) \\
& \leq\left(\widetilde{\alpha}_{n}+\alpha_{n}-\widetilde{\alpha}_{n} \alpha_{n}\right) \phi\left(p, x_{0}\right)+\left(1-\alpha_{n}\right)\left(1-\tilde{\alpha}_{n}\right) \phi\left(p, x_{n}\right) \\
& -\left(1-\tilde{\alpha}_{n}\right) \tilde{\beta}_{n}\left(1-\tilde{\beta}_{n}\right) g\left(\left\|J z_{n}-J T_{n} \tilde{z}_{n}\right\|\right) \text {. }
\end{aligned}
$$


Journal of Applied Mathematics

From (3.17) and (3.20), we have

$$
\begin{aligned}
(1- & \left.\tilde{\alpha}_{n}\right) \tilde{\beta}_{n}\left(1-\tilde{\beta}_{n}\right) g\left(\left\|J z_{n}-J T_{n} \tilde{z}_{n}\right\|\right) \\
\leq & \left(\widetilde{\alpha}_{n}+\alpha_{n}-\widetilde{\alpha}_{n} \alpha_{n}\right) \phi\left(p, x_{0}\right)+\left(\alpha_{n} \widetilde{\alpha}_{n}-\alpha_{n}-\widetilde{\alpha}_{n}\right) \phi\left(p, x_{n}\right)+\phi\left(p, x_{n}\right)-\phi\left(p, u_{n}\right) \\
\leq & \left(\widetilde{\alpha}_{n}+\alpha_{n}-\tilde{\alpha}_{n} \alpha_{n}\right)\left(\phi\left(p, x_{0}\right)-\phi\left(p, x_{n}\right)\right) \\
& +2 p\left\|J u_{n}-J x_{n}\right\|+\left(\left\|x_{n}\right\|-\left\|u_{n}\right\|\right)\left(\left\|x_{n}\right\|+\left\|u_{n}\right\|\right) \longrightarrow 0 \quad(n \longrightarrow \infty),
\end{aligned}
$$

which together with condition (iii) implies that

$$
\left\|J z_{n}-J T_{n} \tilde{z}_{n}\right\| \longrightarrow 0 \quad(n \longrightarrow \infty) .
$$

Since $J$ is uniformly continuous on bounded sets, then

$$
\left\|z_{n}-T_{n} \tilde{z}_{n}\right\| \longrightarrow 0 \quad(n \longrightarrow \infty)
$$

By (3.18) and (3.19), we have

$$
\begin{aligned}
\phi\left(p, b_{n}\right) & \leq \phi\left(p, z_{n}\right) \\
& =\phi\left(p, J^{-1}\left(\alpha_{n} J x_{0}+\left(1-\alpha_{n}\right) J a_{n}\right)\right) \\
& \leq \alpha_{n} \phi\left(p, x_{0}\right)+\left(1-\alpha_{n}\right) \phi\left(p, a_{n}\right) \\
& \leq \alpha_{n} \phi\left(p, x_{0}\right)+\left(1-\alpha_{n}\right)\left(\phi\left(p, x_{n}\right)-\beta_{n}\left(1-\beta_{n}\right) g\left(\left\|J x_{n}-J S_{n} w_{n}\right\|\right)\right) .
\end{aligned}
$$

It follows from (3.20) and (3.24) thatss

$$
\begin{aligned}
\phi\left(p, u_{n}\right) \leq & \tilde{\alpha}_{n} \phi\left(p, x_{0}\right)+\left(1-\tilde{\alpha}_{n}\right) \phi\left(p, b_{n}\right) \\
\leq & \tilde{\alpha}_{n} \phi\left(p, x_{0}\right) \\
& +\left(1-\tilde{\alpha}_{n}\right)\left(\alpha_{n} \phi\left(p, x_{0}\right)+\left(1-\alpha_{n}\right)\left(\phi\left(p, x_{n}\right)-\beta_{n}\left(1-\beta_{n}\right) g\left(\left\|J x_{n}-J S_{n} w_{n}\right\|\right)\right)\right) \\
= & \left(\widetilde{\alpha}_{n}+\alpha_{n}-\tilde{\alpha}_{n} \alpha_{n}\right) \phi\left(p, x_{0}\right)+\left(1-\tilde{\alpha}_{n}\right)\left(1-\alpha_{n}\right) \phi\left(p, x_{n}\right) \\
& -\left(1-\widetilde{\alpha}_{n}\right) \beta_{n}\left(1-\beta_{n}\right) g\left(\left\|J x_{n}-J S_{n} w_{n}\right\|\right) .
\end{aligned}
$$

So by (3.17) and (3.25), we obtain

$$
\begin{aligned}
\left(1-\tilde{\alpha}_{n}\right) \beta_{n}\left(1-\beta_{n}\right) g\left(\left\|J x_{n}-J S_{n} w_{n}\right\|\right) \\
\leq \\
\leq\left(\tilde{\alpha}_{n}+\alpha_{n}-\tilde{\alpha}_{n} \alpha_{n}\right)\left(\phi\left(p, x_{0}\right)-\phi\left(p, x_{n}\right)\right)+\left(\phi\left(p, x_{n}\right)-\phi\left(p, u_{n}\right)\right) \\
\leq\left(\tilde{\alpha}_{n}+\alpha_{n}-\tilde{\alpha}_{n} \alpha_{n}\right)\left(\phi\left(p, x_{0}\right)-\phi\left(p, x_{n}\right)\right)+2 p\left\|J u_{n}-J x_{n}\right\| \\
\quad+\left(\left\|x_{n}\right\|-\left\|u_{n}\right\|\right)\left(\left\|x_{n}\right\|+\left\|u_{n}\right\|\right) \longrightarrow 0 \quad(n \longrightarrow \infty),
\end{aligned}
$$


which together with conditions (i) and (ii) implies that

$$
\left\|J x_{n}-J S_{n} w_{n}\right\| \longrightarrow 0 \quad(n \longrightarrow \infty)
$$

Since $J$ is uniformly continuous on bounded sets, then

$$
\left\|x_{n}-S_{n} w_{n}\right\| \longrightarrow 0 \quad(n \longrightarrow \infty)
$$

It follows from (3.2) that

$$
J z_{n}=\alpha_{n} J x_{0}+\left(1-\alpha_{n}\right)\left(\beta_{n} J x_{n}+\left(1-\beta_{n}\right) J S_{n} J_{r_{n}} v_{n}\right) .
$$

Therefore, from (3.27) and condition (i), we have

$$
\left\|J z_{n}-J x_{n}\right\| \leq \alpha_{n}\left\|J x_{0}-J x_{n}\right\|+\left(1-\alpha_{n}\right)\left(1-\beta_{n}\right)\left\|J S_{n} w_{n}-J x_{n}\right\| \longrightarrow 0 \quad(n \longrightarrow \infty)
$$

Thus,

$$
\left\|z_{n}-x_{n}\right\| \longrightarrow 0 \quad(n \rightarrow \infty)
$$

From (3.7) and (3.9), we have

$$
\begin{aligned}
\phi\left(p, z_{n}\right) \leq & \alpha_{n} \phi\left(p, x_{0}\right)+\left(1-\alpha_{n}\right) \beta_{n} \phi\left(p, x_{n}\right) \\
& +\left(1-\alpha_{n}\right)\left(1-\beta_{n}\right)\left(\phi\left(p, x_{n}\right)+2 \lambda_{n}\left(\frac{2}{c^{2}} \lambda_{n}-\gamma\right)\left\|A x_{n}-A p\right\|^{2}\right) \\
= & \alpha_{n} \phi\left(p, x_{0}\right)+\left(1-\alpha_{n}\right) \phi\left(p, x_{n}\right)+2\left(1-\alpha_{n}\right)\left(1-\beta_{n}\right) \lambda_{n}\left(\frac{2}{c^{2}} \lambda_{n}-\gamma\right)\left\|A x_{n}-A p\right\|^{2},
\end{aligned}
$$

which together with (3.31) and condition (i) implies that

$$
\begin{aligned}
& 2\left(1-\alpha_{n}\right)\left(1-\beta_{n}\right) \lambda_{n}\left(\gamma-\frac{2}{c^{2}} \lambda_{n}\right)\left\|A x_{n}-A p\right\|^{2} \\
& \quad \leq \alpha_{n}\left(\phi\left(p, x_{0}\right)-\phi\left(p, x_{n}\right)\right)+\phi\left(p, x_{n}\right)-\phi\left(p, z_{n}\right) \longrightarrow 0 \quad(n \longrightarrow \infty) .
\end{aligned}
$$

Hence,

$$
\left\|A x_{n}-A p\right\| \longrightarrow 0 \quad(n \longrightarrow \infty)
$$


Journal of Applied Mathematics

From Lemmas 2.1, 2.2, and 2.6, (3.34), and the fact that $\|A x\| \leq\|A x-A p\|$ for all $x \in C$ and $p \in \operatorname{VI}(C, A)$, we have

$$
\begin{aligned}
\phi\left(x_{n}, v_{n}\right) & =\phi\left(x_{n}, \Pi_{C} J^{-1}\left(J x_{n}-\lambda_{n} A x_{n}\right)\right) \\
& \leq \phi\left(x_{n}, J^{-1}\left(J x_{n}-\lambda_{n} A x_{n}\right)\right) \\
& =V\left(x_{n}, J x_{n}-\lambda_{n} A x_{n}\right) \\
& \leq V\left(x_{n}, J x_{n}-\lambda_{n} A x_{n}+\lambda_{n} A x_{n}\right)-2\left\langle J^{-1}\left(J x_{n}-\lambda_{n} A x_{n}\right)-x_{n}, \lambda_{n} A x_{n}\right\rangle \\
& =\phi\left(x_{n}, x_{n}\right)+2 \lambda_{n}\left\|J^{-1}\left(J x_{n}-\lambda_{n} A x_{n}\right)-J^{-1} J x_{n}\right\|\left\|A x_{n}\right\| \\
& \leq 2 \lambda_{n}^{2} \frac{2}{c^{2}}\left\|A x_{n}\right\|^{2} \\
& \leq 2 \lambda_{n}^{2} \frac{2}{c^{2}}\left\|A x_{n}-A p\right\|^{2} \longrightarrow 0 \quad(n \longrightarrow \infty) .
\end{aligned}
$$

This implies that

$$
\left\|x_{n}-v_{n}\right\| \longrightarrow 0 \quad(n \longrightarrow \infty)
$$

Combining (3.28) and (3.36), we have

$$
\left\|v_{n}-S_{n} w_{n}\right\| \longrightarrow 0 \quad(n \longrightarrow \infty)
$$

It follows from (3.6), (3.7), and (3.12) that

$$
\begin{aligned}
\phi\left(p, w_{n}\right) \geq & \frac{\phi\left(p, u_{n}\right)}{\left(1-\tilde{\alpha}_{n}\right)\left(1-\alpha_{n}\right)\left(1-\beta_{n}\right)}-\frac{\left(\widetilde{\alpha}_{n}+\alpha_{n}-\tilde{\alpha}_{n} \alpha_{n}\right) \phi\left(p, x_{0}\right)}{\left(1-\widetilde{\alpha}_{n}\right)\left(1-\alpha_{n}\right)\left(1-\beta_{n}\right)} \\
& -\frac{\left(1-\tilde{\alpha}_{n}\right)\left(1-\alpha_{n}\right) \beta_{n} \phi\left(p, x_{n}\right)}{\left(1-\widetilde{\alpha}_{n}\right)\left(1-\alpha_{n}\right)\left(1-\beta_{n}\right)}
\end{aligned}
$$

By Lemma 2.9, (3.9), and (3.38), we have

$$
\begin{aligned}
\phi\left(w_{n}, v_{n}\right) & =\phi\left(J_{r_{n}} v_{n}, v_{n}\right) \leq \phi\left(p, v_{n}\right)-\phi\left(p, w_{n}\right) \\
& \leq \phi\left(p, x_{n}\right)-\phi\left(p, w_{n}\right) \\
& \leq \frac{\phi\left(p, x_{n}\right)-\phi\left(p, u_{n}\right)}{\left(1-\widetilde{\alpha}_{n}\right)\left(1-\alpha_{n}\right)\left(1-\beta_{n}\right)}+\frac{\widetilde{\alpha}_{n}+\alpha_{n}-\widetilde{\alpha}_{n} \alpha_{n}}{\left(1-\widetilde{\alpha}_{n}\right)\left(1-\alpha_{n}\right)\left(1-\beta_{n}\right)}\left(\phi\left(p, x_{0}\right)-\phi\left(p, x_{n}\right)\right) .
\end{aligned}
$$

So, by (3.17) and conditions (i) and (ii), we have

$$
\phi\left(w_{n}, v_{n}\right) \longrightarrow 0 \quad(n \longrightarrow \infty),
$$


which implies that

$$
\left\|w_{n}-v_{n}\right\| \longrightarrow 0 \quad(n \longrightarrow \infty)
$$

Combining (3.37) and (3.41), we obtain

$$
\left\|w_{n}-S_{n} w_{n}\right\| \longrightarrow 0 \quad(n \longrightarrow \infty)
$$

It follows from (3.6), (3.10), and (3.12) that

$$
\begin{aligned}
\phi\left(p, u_{n}\right) \leq & \phi\left(p, y_{n}\right) \\
\leq & \widetilde{\alpha}_{n} \phi\left(p, x_{0}\right)+\left(1-\tilde{\alpha}_{n}\right) \tilde{\beta}_{n} \phi\left(p, z_{n}\right)+\left(1-\tilde{\alpha}_{n}\right)\left(1-\tilde{\beta}_{n}\right) \phi\left(p, \tilde{z}_{n}\right) \\
\leq & \left(\tilde{\alpha}_{n}+\left(1-\widetilde{\alpha}_{n}\right) \tilde{\beta}_{n} \alpha_{n}\right) \phi\left(p, x_{0}\right) \\
& +\left(1-\tilde{\alpha}_{n}\right)\left(1-\alpha_{n}\right) \tilde{\beta}_{n} \phi\left(p, x_{n}\right)+\left(1-\tilde{\alpha}_{n}\right)\left(1-\tilde{\beta}_{n}\right) \phi\left(p, \tilde{z}_{n}\right),
\end{aligned}
$$

which implies that

$$
\phi\left(p, \tilde{z}_{n}\right) \geq \frac{\phi\left(p, u_{n}\right)}{\left(1-\tilde{\alpha}_{n}\right)\left(1-\tilde{\beta}_{n}\right)}-\frac{\left(\widetilde{\alpha}_{n}+\left(1-\tilde{\alpha}_{n}\right) \tilde{\beta}_{n} \alpha_{n}\right) \phi\left(p, x_{0}\right)}{\left(1-\tilde{\alpha}_{n}\right)\left(1-\tilde{\beta}_{n}\right)}-\frac{\left(1-\tilde{\alpha}_{n}\right)\left(1-\alpha_{n}\right) \tilde{\beta}_{n} \phi\left(p, x_{n}\right)}{\left(1-\tilde{\alpha}_{n}\right)\left(1-\widetilde{\beta}_{n}\right)}
$$

Combining the above inequality, (3.10), and Lemma 2.9, we have

$$
\begin{aligned}
\phi\left(\tilde{z}_{n}, z_{n}\right) & =\phi\left(\tilde{J}_{r_{n}} z_{n}, z_{n}\right) \\
& \leq \phi\left(p, z_{n}\right)-\phi\left(p, \widetilde{z}_{n}\right) \\
& \leq \alpha_{n} \phi\left(p, x_{0}\right)+\left(1-\alpha_{n}\right) \phi\left(p, x_{n}\right)-\phi\left(p, \tilde{z}_{n}\right) \\
& \leq \frac{\phi\left(p, x_{n}\right)-\phi\left(p, u_{n}\right)}{\left(1-\tilde{\alpha}_{n}\right)\left(1-\tilde{\beta}_{n}\right)}+\frac{\left(\alpha_{n}+\tilde{\alpha}_{n}-\alpha_{n} \tilde{\alpha}_{n}\right)}{\left(1-\tilde{\alpha}_{n}\right)\left(1-\tilde{\beta}_{n}\right)}\left(\phi\left(p, x_{0}\right)-\phi\left(p, x_{n}\right)\right) .
\end{aligned}
$$

By conditions (i) and (iii), (3.17), and (3.45), we have

$$
\phi\left(\tilde{z}_{n}, z_{n}\right) \longrightarrow 0 \quad(n \longrightarrow \infty),
$$

which implies that

$$
\left\|\tilde{z}_{n}-z_{n}\right\| \longrightarrow 0 \quad(n \longrightarrow \infty) .
$$


It follows from (3.23) and (3.47) that

$$
\left\|\tilde{z}_{n}-T_{n} \tilde{z}_{n}\right\| \longrightarrow 0 \quad(n \longrightarrow \infty)
$$

Step 3. Now we show that $\omega_{w}\left(\left\{x_{n}\right\}\right) \subset \Omega:=\left(\cap_{n=0}^{\infty} F\left(T_{n}\right)\right) \cap\left(\cap_{n=0}^{\infty} F\left(S_{n}\right)\right) \cap \operatorname{VI}(C, A) \cap$ GMEP $\cap T^{-1} 0 \cap \widetilde{T}^{-1} 0$, where

$$
\omega_{w}\left(\left\{x_{n}\right\}\right)=\left\{x^{*} \in C: x_{n_{k}} \rightarrow x^{*} \text { for some sequence }\left\{n_{k}\right\} \subset\{n\} \text { with } n_{k} \uparrow \infty\right\} \text {. }
$$

Indeed, since $\left\{x_{n}\right\}$ is bounded and $X$ is reflexive, we know that $\omega_{w}\left(\left\{x_{n}\right\}\right) \neq \emptyset$. For any arbitrary $x^{*} \in \omega_{w}\left(\left\{x_{n}\right\}\right)$, there exists a subsequence $\left\{x_{n_{k}}\right\}$ of $\left\{x_{n}\right\}$ such that $x_{n_{k}} \rightarrow x^{*}$. From (3.36), we have $v_{n_{k}} \rightarrow x^{*}$. Since $\left\{T_{n}\right\},\left\{S_{n}\right\}$ satisfy NST-conditions, from (3.42) and (3.48) we have $x^{*} \in\left(\cap_{n=0}^{\infty} F\left(T_{n}\right)\right) \cap\left(\cap_{n=0}^{\infty} F\left(S_{n}\right)\right)$.

Let $S \subset E \times E^{*}$ be an operator as follows:

$$
S v= \begin{cases}A v+N_{C}(v), & v \in C, \\ \emptyset, & v \notin C .\end{cases}
$$

By Lemma 2.5, $S$ is maximal monotone and $S^{-1}(0)=\operatorname{VI}(C, A)$. Let $(v, w) \in G(S)$. Since $w \in$ $S v=A v+N_{C}(v)$, we have $w-A v \in N_{C}(v)$. Moreover, $v_{n} \in C$ implies that

$$
\left\langle v-v_{n}, w-A v\right\rangle \geq 0
$$

On the other hand, it follows from $v_{n}=\Pi_{C} J^{-1}\left(J x_{n}-\lambda_{n} A x_{n}\right)$ and Lemma 2.2 that

$$
\left\langle v-v_{n}, J v_{n}-\left(J x_{n}-\lambda_{n} A x_{n}\right)\right\rangle \geq 0,
$$

and hence

$$
\left\langle v-v_{n}, \frac{J x_{n}-J v_{n}}{\lambda_{n}}-A x_{n}\right\rangle \leq 0
$$


So, from (3.51), (3.53), and $A$ being $1 / \gamma$-Lipschitz continuous, we obtain

$$
\begin{aligned}
\left\langle v-v_{n}, w\right\rangle & \geq\left\langle v-v_{n}, A v\right\rangle \\
& \geq\left\langle v-v_{n}, A v\right\rangle+\left\langle v-v_{n} \frac{J x_{n}-J v_{n}}{\lambda_{n}}-A x_{n}\right\rangle \\
& =\left\langle v-v_{n}, A v-A x_{n}+\frac{J x_{n}-J v_{n}}{\lambda_{n}}\right\rangle \\
& \geq\left\langle v-v_{n}, A v-A v_{n}\right\rangle+\left\langle v-v_{n}, A v_{n}-A x_{n}\right\rangle+\left\langle v-v_{n}, \frac{J x_{n}-J v_{n}}{\lambda_{n}}\right\rangle \\
& \geq-\left\|v-v_{n}\right\|\left\|A v_{n}-A x_{n}\right\|-\left\|v-v_{n}\right\|\left\|\frac{J x_{n}-J v_{n}}{a}\right\| \\
& \geq \frac{-1}{r\left\|v-v_{n}\right\|\left\|v_{n}-x_{n}\right\|}-\left\|v-v_{n}\right\|\left\|\frac{J x_{n}-J v_{n}}{a}\right\| .
\end{aligned}
$$

Since $J$ is uniformly continuous on bounded sets, by (3.36) and replacing $n$ by $n_{k}$ in (3.54), as $k \rightarrow \infty$ we have $\left\langle v-x^{*}, w\right\rangle \geq 0$. Thus, $x^{*} \in S^{-1}(0)$, and hence $x^{*} \in \operatorname{VI}(C, A)$.

Next we show that $x^{*} \in \mathrm{GMEP}=F\left(K_{r}\right)$. Let $H\left(u_{n}, y\right)=\Theta\left(u_{n}, y\right)+\left\langle B u_{n}, y-u_{n}\right\rangle+$ $\varphi(y)-\varphi\left(u_{n}\right)$, for all $y \in C$. It follows from (3.2) that

$$
J y_{n}=\tilde{\alpha}_{n} J x_{0}+\left(1-\tilde{\alpha}_{n}\right)\left(\tilde{\beta}_{n} J z_{n}+\left(1-\tilde{\beta}_{n}\right) J T_{n} \widetilde{J}_{r_{n}} z_{n}\right)
$$

hence, from (3.22) and condition (i), we have

$$
\left\|J y_{n}-J z_{n}\right\| \leq \tilde{\alpha}_{n}\left\|J x_{0}-J z_{n}\right\|+\left(1-\tilde{\alpha}_{n}\right)\left(1-\tilde{\beta}_{n}\right)\left\|J T_{n} \widetilde{J}_{r_{n}} z_{n}-J z_{n}\right\| \longrightarrow 0 \quad(n \longrightarrow \infty),
$$

which implies that

$$
\left\|y_{n}-z_{n}\right\| \longrightarrow 0 \quad(n \longrightarrow \infty)
$$

From (3.17), (3.31), and (3.57), we obtain

$$
\left\|y_{n}-u_{n}\right\| \longrightarrow 0 \quad(n \longrightarrow \infty)
$$

Thus, $u_{n_{k}} \rightarrow x^{*}, y_{n_{k}} \rightarrow x^{*}(k \rightarrow \infty)$. Since $J$ is uniformly continuous on bounded sets, from (3.58) we have $\lim _{k \rightarrow \infty}\left\|J u_{n_{k}}-J y_{n_{k}}\right\|=0$. Therefore, it follows from $t_{n_{k}} \geq c^{*}$ that $\| J u_{n_{k}}-$ $J y_{n_{k}} \| / t_{n_{k}} \rightarrow 0(n \rightarrow \infty)$. Since $u_{n}=K_{t_{n}} y_{n}$, we have

$$
H\left(u_{n}, y\right)+\frac{1}{t_{n}}\left\langle y-u_{n}, J u_{n}-J y_{n}\right\rangle \geq 0, \quad \forall y \in C
$$


Combining the above inequality, (A2) and (A4), we get

$$
\left\|y-u_{n}\right\| \frac{\left\|J u_{n}-J y_{n}\right\|}{t_{n}} \geq \frac{1}{t_{n}}\left\langle y-u_{n}, J u_{n}-J y_{n}\right\rangle \geq-H\left(u_{n}, y\right) \geq H\left(y, u_{n}\right), \quad \forall y \in C .
$$

Replacing $n$ by $n_{k}$ and taking the limit as $k \rightarrow \infty$ in the above inequality and by (A4), we have $H\left(y, x^{*}\right) \leq 0$, for all $y \in C$. For any $t \in(0,1)$ and $y \in C$, define $y_{t}=t y+(1-t) x^{*} \in C$. So $H\left(y_{t}, x^{*}\right) \leq 0$. From (A1) and (A4), we have

$$
0=H\left(y_{t}, y_{t}\right) \leq t H\left(y_{t}, y\right)+(1-t) H\left(y_{t}, x^{*}\right) \leq t H\left(y_{t}, y\right)
$$

that is, $H\left(y_{t}, y\right) \geq 0$. Thus, from (A3), let $t \rightarrow 0$, we have $H\left(x^{*}, y\right) \geq 0$, for all $y \in C$, which implies that $x^{*} \in$ GMEP.

From (3.31), (3.36), (3.41), and (3.47), similar to the proof of Step 5 in Theorem 3.1 of [19], we have $x^{*} \in T^{-1} 0 \cap \widetilde{T}^{-1} 0$. Therefore, $\omega_{w}\left(\left\{x_{n}\right\}\right) \subset \Omega$.

Step 4. Finally we prove that $\left\{x_{n}\right\}$ converges strongly to $\tilde{x}=\Pi_{\Omega} x_{0}$.

It follows from Step 6 in Theorem 3.1 of [19] that we have the conclusion. This completes the proof.

If $A \equiv 0$, then we have the following result from Theorem 3.1.

Corollary 3.2. Let $E$ be a real uniformly smooth and uniformly convex Banach space and $C$ a nonempty, closed, and convex subset of $E$. Let $B: C \rightarrow E^{*}$ be a monotone continuous mapping. Let $\left\{T_{n}\right\},\left\{S_{n}\right\}$ be two countable families of relatively quasi-nonexpansive mappings from $C$ into itself satisfying NST-conditions such that $\Omega:=\left(\cap_{n=0}^{\infty} F\left(T_{n}\right)\right) \cap\left(\cap_{n=0}^{\infty} F\left(S_{n}\right)\right) \cap G M E P \cap T^{-1} 0 \cap \widetilde{T}^{-1} 0 \neq \emptyset$. Let $\left\{t_{n}\right\} \subset\left[c^{*},+\infty\right)$ for some $c^{*}>0$ and $\left\{r_{n}\right\} \subset(0,+\infty)$ satisfy $\lim \inf _{n \rightarrow \infty} r_{n}>0$. Let $\left\{x_{n}\right\}$ be the sequence generated by

$$
\begin{aligned}
& x_{0} \in C, \text { chosen arbitrarily, } \\
& z_{n}=J^{-1}\left(\alpha_{n} J x_{0}+\left(1-\alpha_{n}\right)\left(\beta_{n} J x_{n}+\left(1-\beta_{n}\right) J S_{n} J_{r_{n}} x_{n}\right)\right), \\
& y_{n}=J^{-1}\left(\tilde{\alpha}_{n} J x_{0}+\left(1-\tilde{\alpha}_{n}\right)\left(\tilde{\beta}_{n} J z_{n}+\left(1-\tilde{\beta}_{n}\right) J T_{n} \tilde{J}_{r_{n}} z_{n}\right)\right), \\
& u_{n}=K_{t_{n}} y_{n}, \\
& H_{n}=\left\{z \in C: \phi\left(z, u_{n}\right) \leq\left(\tilde{\alpha}_{n}+\left(1-\tilde{\alpha}_{n}\right) \alpha_{n}\right) \phi\left(z, x_{0}\right)+\left(1-\tilde{\alpha}_{n}\right)\left(1-\alpha_{n}\right) \phi\left(z, x_{n}\right)\right\}, \\
& W_{n}=\left\{z \in C:\left\langle x_{n}-z, J x_{0}-J x_{n}\right\rangle \geq 0\right\}, \\
& x_{n+1}=\Pi_{H_{n} \cap W_{n}} x_{0}, n \geq 0,
\end{aligned}
$$

where $J$ is the normalized duality mapping, $\left\{\alpha_{n}\right\},\left\{\beta_{n}\right\},\left\{\tilde{\alpha}_{n}\right\}$, and $\left\{\tilde{\beta}_{n}\right\}$ are four sequences in $[0,1]$, and $K_{r}$ is defined by $(*)$. The following conditions hold: 
(i) $\lim _{n \rightarrow \infty} \alpha_{n}=\lim _{n \rightarrow \infty} \tilde{\alpha}_{n}=0$;

(ii) $\liminf _{n \rightarrow \infty} \beta_{n}\left(1-\beta_{n}\right)>0$;

(iii) $\liminf \operatorname{in}_{n \rightarrow \infty} \tilde{\beta}_{n}\left(1-\tilde{\beta}_{n}\right)>0$.

Then $\left\{x_{n}\right\}$ converges strongly to $\Pi_{\Omega} x_{0}$.

Proof. From the proof of Theorem 3.1, (2.4) is used in proving (3.9), (3.34), and (3.36). Since $A \equiv 0, v_{n}=x_{n}$ for all $n \geq 0$, so uniformly smooth and 2-uniformly convex Banach space $E$ can be weakened to uniformly smooth and uniformly convex Banach space. Thus, from Theorem 3.1, the proof is completed.

Remark 3.3. If $S_{n}=T_{n}=I, r_{n}=t_{n}$ for all $n \geq 0$, and $\varphi=0$, then Corollary 3.2 reduces to Theorem 3.1 in [19].

\section{Acknowledgments}

The paper is supported by the Research Project of Shaoxing University (no. 09LG1002). The author is extremely grateful to the referees for their useful suggestions that improved the content of the paper.

\section{References}

[1] E. Blum and W. Oettli, "From optimization and variational inequalities to equilibrium problems," The Mathematics Student, vol. 63, no. 1-4, pp. 123-145, 1994.

[2] S.-S. Zhang, "Generalized mixed equilibrium problem in Banach spaces," Applied Mathematics and Mechanics, vol. 30, no. 9, pp. 1105-1112, 2009.

[3] L.-C. Ceng and J.-C. Yao, "A hybrid iterative scheme for mixed equilibrium problems and fixed point problems," Journal of Computational and Applied Mathematics, vol. 214, no. 1, pp. 186-201, 2008.

[4] S. Takahashi and W. Takahashi, "Strong convergence theorem for a generalized equilibrium problem and a nonexpansive mapping in a Hilbert space," Nonlinear Analysis, vol. 69, no. 3, pp. 1025-1033, 2008.

[5] W. Takahashi and K. Zembayashi, "Strong and weak convergence theorems for equilibrium problems and relatively nonexpansive mappings in Banach spaces," Nonlinear Analysis, vol. 70, no. 1, pp. 45-57, 2009.

[6] Y.-Q. Wang and L.-C. Zeng, "Hybrid projection method for generalized mixed equilibrium problems, variational inequality problems, and fixed point problems in Banach spaces," Applied Mathematics and Mechanics, vol. 32, no. 2, pp. 251-264, 2011.

[7] H. K. Xu, “Inequalities in Banach spaces with applications," Nonlinear Analysis, vol. 16, no. 12, pp. 1127-1138, 1991.

[8] W. Takahashi, Nonlinear Functional Analysis, Kindikagaku, Tokyo, Japan, 1988.

[9] R. T. Rockafellar, "On the maximality of sums of nonlinear monotone operators," Transactions of the American Mathematical Society, vol. 149, pp. 75-88, 1970.

[10] Y. I. Alber, "Metric and generalized projection operators in Banach spaces: properties and applications," in Theory and Applications of Nonlinear Operators of Accretive and Monotone Type, A. G. Kartsatos, Ed., vol. 178 of Lecture Notes in Pure and Applied Mathematics, pp. 15-50, Dekker, New York, NY, USA, 1996.

[11] S. Kamimura and W. Takahashi, "Strong convergence of a proximal-type algorithm in a Banach space," SIAM Journal on Optimization, vol. 13, no. 3, pp. 938-945, 2002.

[12] S. Reich, "A weak convergence theorem for the alternating method with Bregman distances," in Theory and Applications of Nonlinear Operators of Accretive and Monotone Type, A. G. Kartsatos, Ed., vol. 178 of Lecture Notes in Pure and Applied Mathematics, pp. 313-318, Dekker, New York, NY, USA, 1996.

[13] D. Butnariu, S. Reich, and A. J. Zaslavski, "Asymptotic behavior of relatively nonexpansive operators in Banach spaces," Journal of Applied Analysis, vol. 7, no. 2, pp. 151-174, 2001. 
[14] D. Butnariu, S. Reich, and A. J. Zaslavski, "Weak convergence of orbits of nonlinear operators in reflexive Banach spaces," Numerical Functional Analysis and Optimization, vol. 24, no. 5-6, pp. 489-508, 2003.

[15] R. T. Rockafellar, "Monotone operators and the proximal point algorithm," SIAM Journal on Control and Optimization, vol. 14, no. 5, pp. 877-898, 1976.

[16] F. Kohsaka and W. Takahashi, "Strong convergence of an iterative sequence for maximal monotone operators in a Banach space," Abstract and Applied Analysis, no. 3, pp. 239-249, 2004.

[17] S. Kamimura, F. Kohsaka, and W. Takahashi, "Weak and strong convergence theorems for maximal monotone operators in a Banach space," Set-Valued Analysis, vol. 12, no. 4, pp. 417-429, 2004.

[18] S. Saewan and P. Kumam, "A hybrid iterative scheme for a maximal monotone operator and two countable families of relatively quasi-nonexpansive mappings for generalized mixed equilibrium and variational inequality problems," Abstract and Applied Analysis, vol. 2010, Article ID 123027, 31 pages, 2010.

[19] L.-C. Zeng, Q. H. Ansari, D. S. Shyu, and J.-C. Yao, "Strong and weak convergence theorems for common solutions of generalized equilibrium problems and zeros of maximal monotone operators," Fixed Point Theory and Applications, vol. 2010, Article ID 590278, 33 pages, 2010.

[20] S. Saewan and P. Kumam, "Strong convergence theorems for countable families of uniformly quasi-øasymptotically nonexpansive mappings and a system of generalized mixed equilibrium problems," Abstract and Applied Analysis, vol. 2011, Article ID 701675, 27 pages, 2011.

[21] K. Wattanawitoon and P. Kumam, "Hybrid proximal-point methods for zeros of maximal monotone operators, variational inequalities and mixed equilibrium problems," International Journal of Mathematics and Mathematical Sciences, Article ID 174796, 31 pages, 2011.

[22] S. Saewan and P. Kumam, "A modied hybrid projection method for solving generalized mixed equilibrium problems and fixed point problems in Banach spaces," Journal of Computational and Applied Mathematics, vol. 62, pp. 1723-1735, 2011.

[23] K. Wattanawitoon and P. Kumam, "Generalized mixed equilibrium problems for maximal monotone operators and two relatively quasi-nonexpansive mappings," Thai Journal of Mathematics, vol. 9, no. 1, pp. 165-189, 2011.

[24] K. Nakajo, K. Shimoji, and W. Takahashi, "Strong convergence theorems by the hybrid method for families of nonexpansive mappings in Hilbert spaces," Taiwanese Journal of Mathematics, vol. 10, no. 2, pp. 339-360, 2006.

[25] D. Pascali and S. Sburlan, Nonlinear Mappings of Monotone Type, Editura Academiae, Bucaresti, Romania, 1978

[26] Y. J. Cho, H. Zhou, and G. Guo, "Weak and strong convergence theorems for three-step iterations with errors for asymptotically nonexpansive mappings," Computers \& Mathematics with Applications, vol. 47, no. 4-5, pp. 707-717, 2004.

[27] F. Kohsaka and W. Takahashi, "Existence and approximation of fixed points of firmly nonexpansivetype mappings in Banach spaces," SIAM Journal on Optimization, vol. 19, no. 2, pp. 824-835, 2008.

[28] X. Qin, Y. J. Cho, and S. M. Kang, "Convergence theorems of common elements for equilibrium problems and fixed point problems in Banach spaces," Journal of Computational and Applied Mathematics, vol. 225, no. 1, pp. 20-30, 2009. 


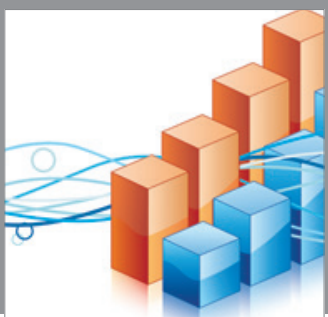

Advances in

Operations Research

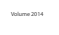

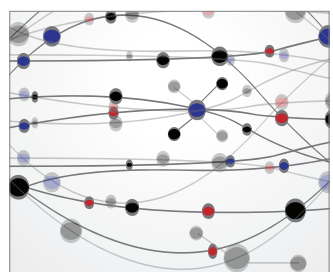

\section{The Scientific} World Journal
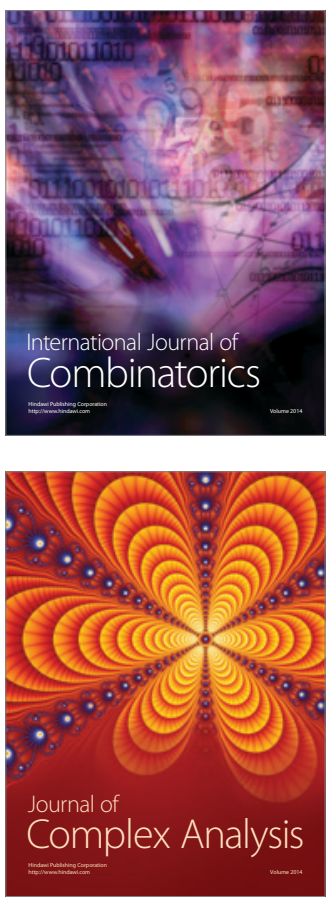

International Journal of

Mathematics and

Mathematical

Sciences
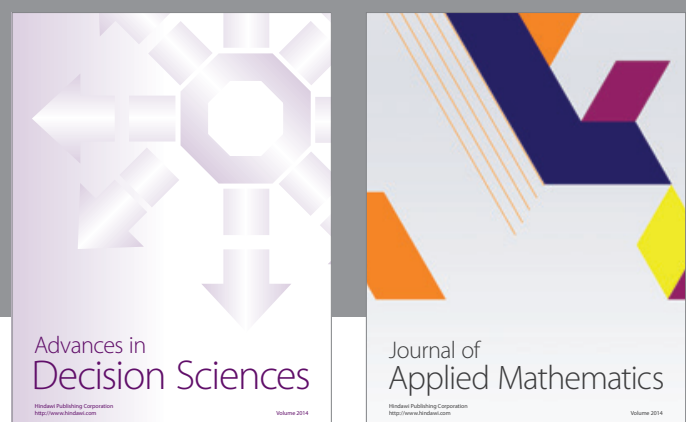

Journal of

Applied Mathematics
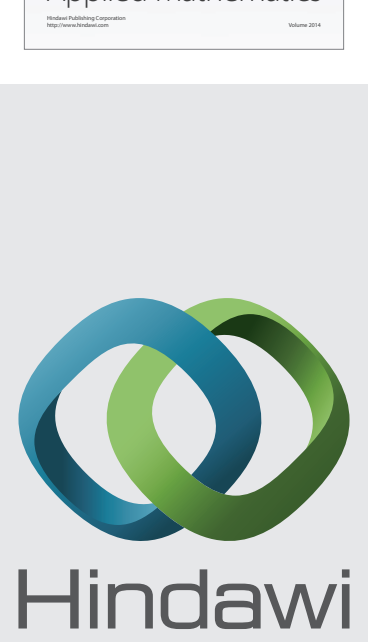

Submit your manuscripts at http://www.hindawi.com
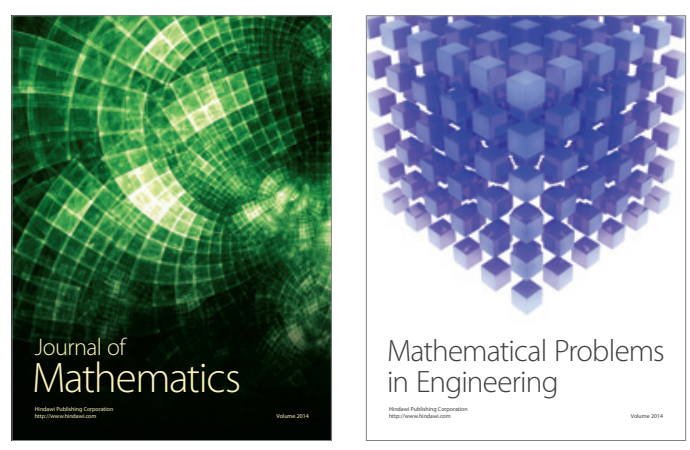

Mathematical Problems in Engineering
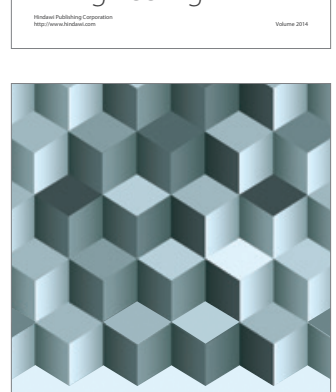

Journal of

Function Spaces
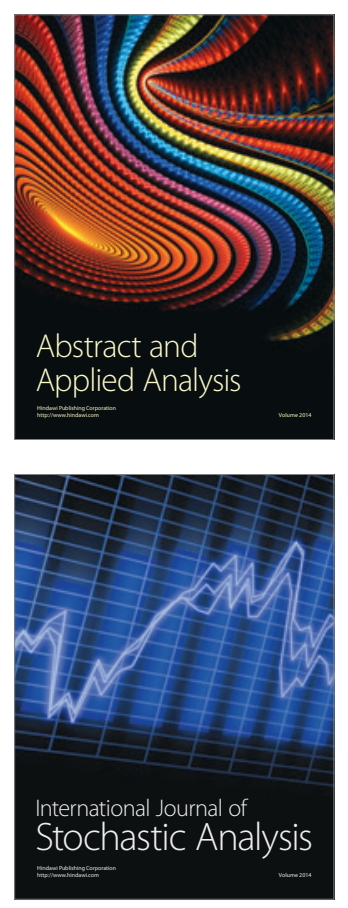

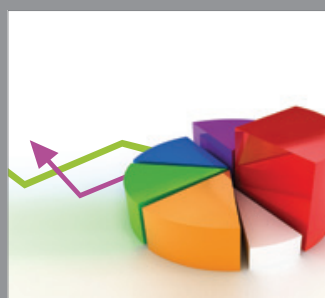

ournal of

Probability and Statistics

Promensencen
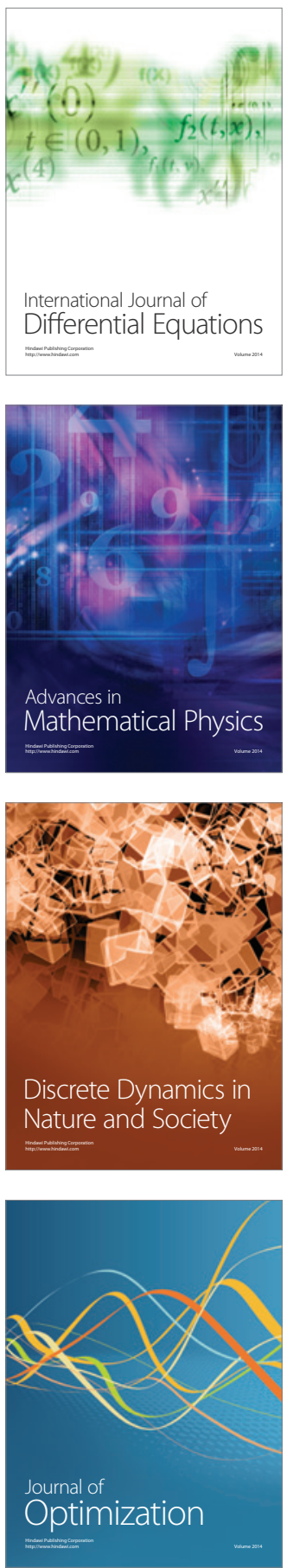